\title{
Induction of estrus using human menopausal gonadotrophin in Iraqi Awassi ewes
}

\author{
E.K. Hussein ${ }^{\circledR}$, U.T. Naoman ${ }^{(D)}$ and R.R. Al-Ajeli 1 \\ Department of Surgery and Theriogenology, College of Veterinary Medicine, University of Mosul, Mosul, Iraq
}

\begin{tabular}{l} 
Article information \\
\hline Article history: \\
Received May 17, 2020 \\
Accepted July 14, 2020 \\
Available online June 24, 2021 \\
\hline Keywords: \\
HMG \\
PMSG \\
Hormone \\
Awassi ewes \\
Estrus synchronization \\
\hline Correspondence: \\
U.T. Naoman \\
uday.naoman@uomosul.edu.iq
\end{tabular}

DOI: 10.33899/ijvs.2020.127132.1466, (O2021, College of Veterinary Medicine, University of Mosul.

This is an open access article under the CC BY 4.0 license (http://creativecommons.org/licenses/by/4.0/).

\section{Introduction}

Awassi sheep is regarded as highly productive native dairy breed as well as producing wool and meat, which play an important role in the economic life of a farmer and their families (1,2). Previous studies have reported that synchronization in sheep is achieved by control of the luteal phase of the estrus cycle, either by providing exogenous progesterone or by inducing premature luteolysis and extend the luteal phase or shorten this phase by prematurely regressing existing corpora lutea (3). The success of hormonal treatment for estrus synchronization depends on the productive status of ewes (4), the season of the year (5), the type of hormonal protocol and the method of administration $(3,6)$. Multiple ovulation programs are also possible with the use of estrus synchronization for improving herd productivity (7). Gonadotrophin hormones are essential for growth, maturation and ovulation were a complete 
successful estrus cycle in ewes (8). Various protocols have been developed for estrus induction, superovulation and to increase the fertility in the ewes such as Follicle Stimulating Hormone (FSH), equine Chorionic Gonadotropin (eCG) or Pregnant Mare Serum Gonadotropin (PMSG), Gonadotropin hormone $(\mathrm{GnRH})$, Melatonin, immunized against synthetic inhibin- $\alpha$ and Prostaglandin (PGF2 $\alpha$ ) with or without using Progesterone, in or out of reproductive seasons with varying degrees of success $(9,10)$. The variation among using these hormones and its results, may be related to the variation in sheep breed, doses of hormones, seasons, mating system and types of hormones (3). Human Menopausal gonadotropins or HMG is one of the exogenous gonadotropins hormone which have been used for superovulation and for the treatment of low fertility in women and men with more acceptable of successful, which contain an equal ratio of FSH and LH become available in the late 1960s, and it's also known for using in superovulation and embryo transfer in cattle, mare, and swine (11). Pregnant Mare Serum Gonadotropins or PMSG hormone is one of the Gonadotropins hormones which have been used widely as an exogenous hormone for estrus synchronization programs and increase fertility in ewes due to its FSH- and LH-like actions hormone (12), leading to ovulation and luteinizing of granulosa and theca cells to form luteal cells for subsequent progesterone secretion. This protocol ensures appropriate progesterone concentration to induce turnover and ovulation of a nonpersist follicle (13). A high percentage of estrus successful rate has been recorded following the application of intravaginal sponges contain 30-40 mg of progesterone hormone for 12-14 d with different doses of PMSG (14). Controlled internal drug release (CIDR) is effective when used with PMSG in ewes (15). PMSG hormone is required to stimulate follicle growth, leading to high ovulation rate by an estrus animal out of the breeding season (16).

It is necessary to applied superovulation programs to increase total numbers of animals, twins percentage with all available methods, so the study was designed to compare between using HMG and PMSG in estrus synchronization programs and normal gestation period with recorded parturition with/or without problems.

\section{Materials and methods}

\section{Location of the study}

The study was carried out at a farm located in Kokagli district, Mosul city, Nineveh province at Northern of Iraq its located 36.34 Latitude and 43.13 Longitude and it's situated at elevation 288 meter above sea level. It carried out earlier to breeding season started from the first of June 2018 until all ewes lambing in the middle of November 2018.

\section{Animal of the study}

Sixty Iraqi Awassi ewes aged 2-4 years and weighted 35$45 \mathrm{~kg}$ were used in this study. animals were fed on $1.5-2 \mathrm{~kg}$ of mixture food during the entire period of study, in addition, the ewes grazed daily for $6-8 \mathrm{~h}$ on pasture with water freely in all the day. All animals were healthy and had good body condition. Animals were treated against sheep disease like sheep pox, enterotoxaemia, and external and internal parasite infection during the period of study. Animals were examined for pregnancy diagnosis or reproductive disorders by using $B$ mode ultrasonography. All groups of ewes were served naturally by using fifteen proven fertile rams (five males for each group) which were freely grazed and kept with the ewes in the same condition. Detection of estrus cycle was depend on the signs of estrus including restlessness, seeking for rams and rubbing their body and neck against the ram, stand still during mounting, were recording for each ewe.

\section{Experimental design}

The ewes were divided randomly into three groups $(n=20$ ewes for each group). all ewes comprised of intra-vaginal sponge impregnated by progesterone (Synncropart $40 \mathrm{mg}$ sheep sponge, Ceva Sante Animal, France) for 12 days. Group I: Control Group (C): ewes were injected intramuscularly with $2 \mathrm{ml}$ of sterile saline solution on the same day of sponge withdrawal. Group II: HMG Treatment Group (HMG): ewes were injected intramuscularly with 300 IU of HMG (Pergonal 150 IU for each vial, production of Serum Institute of India Ltd. India) on the same day of sponge withdrawal. Group III: PMSG Treatment Group (PMSG): ewes were injected intramuscularly with $500 \mathrm{IU}$ of PMSG (Folligon; Intervet International B.V., Boxmeer, Holland) on the same day of sponge withdrawal. Ewes were kept monitoring till estrus signs were showed, all ewes showed signs of estrus after $72 \mathrm{~h}$ after sponge withdrawal. Natural mating for all ewes in estrus also recorded as summarized in Figure 1. All ewes were examined monthly by using B mode ultrasonography for pregnancy diagnosis and kept under monitoring during the gestational period. Lambing of pregnant ewes and twining rate (number of twins), fetal abnormalities and dystocia were recorded for all studied groups. The criteria which considered are: clinical examination to detection of ring womb cases and failure of ewes to get parturition after 6 hours from starting labor signs and treated under authors supervising every 30 minute from beginning of labor signs.

\section{Statistical analysis}

Data of the study were expressed as Mean + SE. Normally distributed data were compared by ANOVA 1 (One-Way Analysis of Variance). Significant differences were determined by Duncan's Multiple Range Test. statistical analyses were performed by Sigma Stat (Jandel scientific software V3.1) and $(\mathrm{P}<0.05)$ was consider as statistically significant. 


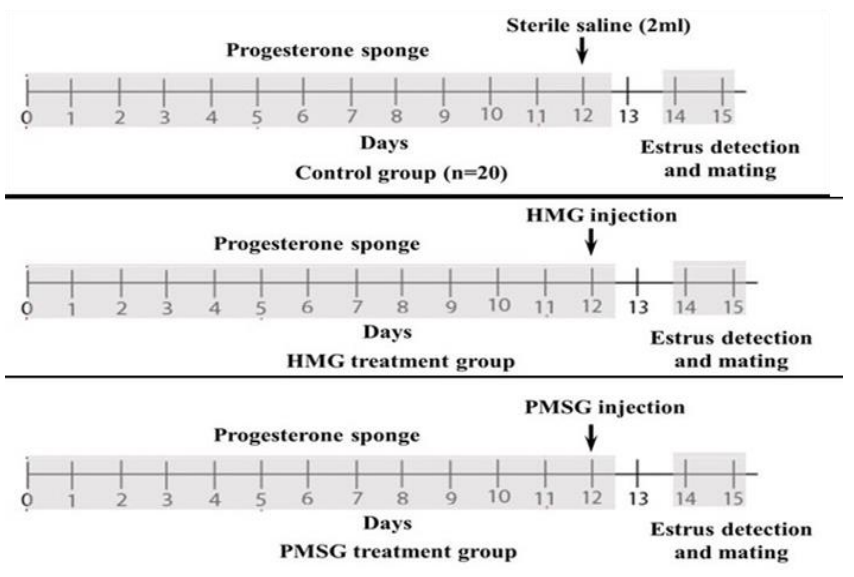

Figure 1: Time scale of hormones injection and estrus detection in the studied groups.

\section{Results}

Data of this study were summarized in table 1 for all three groups. Estrus response percentages were 40\% (8/20), 85\%
$(17 / 20)$ and $90 \%(18 / 20)$ in control group (C), HMG and PMSG groups $(\mathrm{P}<0.05)$, respectively (control group significantly change $\mathrm{P}<0.05$ ); while Estrus response times show changes in its means which were $71 \pm 1.9,72 \pm 0.9$ and $71 \pm 1.0$ hours, respectively with no significant changes between control and PMSG groups. Estrus durations means were $31 \pm 0.5,31 \pm 0.7$ and $31.0 \pm 0.5$ hours in all groups, respectively without significant changes.

Pregnancy data were estimated in table 2 for all studied groups. The pregnancy rates were $30 \%$ (6/20), 85\% (17/20) and $90 \%(18 / 20)$ in the studied groups (control group significantly change $\mathrm{P}<0.05$ ), respectively. The Gestational periods were $155 \pm 1.4,155 \pm .1 .3,155 \pm .1 .6$ days in the studied groups, respectively. The twining rate were $1.0 \pm 0.3$ and $1.1 \pm 0.1$ in both HMG and PMSG groups, respectively without significant changes $(\mathrm{P}<0.05)$, while the control group recorded no twining data. The result of this study recorded a rise of some birth problems which were dystocia and pregnancy Toxemia (according to the clinical signs) in four cases which recorded in the PMSG groups and one case of dystocia in the HMG group with mild of severity of each one.

Table 1: Shows Estrus values differences (\%) between the treatment's groups

\begin{tabular}{lcccc}
\hline Groups & $\mathrm{N}$ & Estrus Response $\%$ & Onset of Estrus(Hours) mean \pm SE & Duration of Estrus(hours) mean \pm SE \\
\hline Control & 20 & A 40 (8/20) & $71 \pm 1.9 \mathrm{~A}$ & $31.0 \pm 0.5 \mathrm{~A}$ \\
HMG & 20 & B 85 (17/20) & $72 \pm 0.9 \mathrm{~A}$ & $31.0 \pm 0.7 \mathrm{~A}$ \\
PMSG & 20 & B 90 $(18 / 20)$ & $71 \pm 1.0 \mathrm{~A}$ & $31.0 \pm 0.5 \mathrm{~A}$ \\
\hline
\end{tabular}

Values are expressed as Means \pm SE, Different letters denote significantly different at $(\mathrm{P}<0.05)$.

Table 2: Show pregnancy values differences $(\%)$ between the treatments group

\begin{tabular}{lccccc}
\hline \multirow{2}{*}{ Groups } & Pregnancy\% & $\begin{array}{c}\text { Gestational period (days) } \\
\text { mean } \pm \text { SE }\end{array}$ & $\begin{array}{c}\text { Twining rate } \\
\text { mean } \pm \text { SE }\end{array}$ & \multicolumn{2}{c}{ Lambing problems } \\
\cline { 4 - 6 } Control & $30(6 / 20) \mathrm{A}$ & $155 \pm 1.4 \mathrm{~A}$ & $0.0 \pm 0.0 \mathrm{~A}$ & - & - \\
HMG & $85(17 / 20) \mathrm{B}$ & $155 \pm 1.3 \mathrm{~A}$ & $1.1 \pm 0.3 \mathrm{~B}$ & 1 & - \\
PMSG & $90(18 / 20) \mathrm{B}$ & $155 \pm 1.6 \mathrm{~A}$ & $1.0 \pm 0.1 \mathrm{~B}$ & 3 & 1 \\
\hline
\end{tabular}

Values are expressed as Means \pm SE, Different letters mean significantly different at $(\mathrm{P}<0.05)$.

\section{Discussion}

The result of this study recorded high percentage of successful rate when using Human Menopausal Gonadotropin in estrus synchronization protocol with progesterone as intra-vaginal sponges during non-breeding season in Iraqi Awassi ewes with similar or slightly effects compared with PMSG but without significantly changes. Both hormones showed similar results for estrus response percentages, estrus response times and estrus durations time with no significant changes in its means but control groups recorded lower data in estrus response percentage when comparing HMG and PMSG groups. The present results were in agreement with the previous reports that referred to using PMSG hormone as a most successful hormone for estrus synchronization program in or out of breeding season $(18,19)$. This effect may be due to the action of PMSG hormone as gonadotropins which increase the number of the growing follicle, ovulation rate, litter size, and its effect on IGF-1 which plays an important role in reproductive metabolic signals of reproductive system and increase numbers of medium estrogenic follicles $(20,21)$.

The effect of HMG may be due to its FSH- and LH-like action to stimulate ovaries to produce follicle and show estrus signs with a high rate of pregnancy (14). The requirement for using HMG (Pergonal) for estrus synchronization program are many, first, it is successfully proven effect in cattle and camel and swine and secondly, its 
action has been proven in human, where used for treated of subfertility in men and women couples (22). The other advantage for using HMG in estrus synchronization instead of some Gonadotropins or Gonadotropin like is due to its save usage without any obstetric problems which were reported by the use of PMSG (23). The long half-life of PMSG can disadvantage since it may cause over and/or prolonged stimulation, leading to a second wave of follicular development after ovulation, so PMSG treatment needs to be neutralized by PMSG antiserum to prevent the secondary development of ovarian follicles (24).

The percentage of pregnancy rate showed highly significant changes between control group in comparison with HMG and PMSG groups and the differentiation related to the change in the percentage of estrus synchronization response. The gestational period in the three groups show no significant changes. Twining rate also show no significant changes between HMG and PMSG groups. In addition, a rise of some labor problems were recorded in PMSG treated group, such as dystocia (three cases) and pregnancy toxemia (one case), which not record in HMG group except in the case of dystocia (one case). There was no clear correlation between the recorded birth disorder with using gonadotropin during estrus synchronization programs, but some previous reports by Park et al. (23) and Summon et al. (24) were suggest that the excess gonadotropin stimulation may cause side effect, Such as impairment of reproductive function and maternal environment. The changing in uterus environment and impairment of reproductive function may be lead to difficult birth or dystocia (25). The mechanism of parturition depended up on hormones or tissue response to hormonal secretion, Calcium, Magnesium, Sodium, Vitamin A and other contribute with this mechanisms (26), any disturbance may be leading to dystocia if discard other mechanical causes of dystocia (27). Although the current study recorded the emergence of dystocia and pregnancy toxemia after the use of the hormones, but It is not possible to say for sure that their use led to the emergence of these cases, and therefore we recommend more studies to investigate the topic.

\section{Conclusion}

It can be concluded that Estrus synchronization in Iraqi Awassi ewes by using HMG or PMSG in does (300 IU), (500 IU) respectively have been indicated, in the present study, with a good estrus response and pregnancy rate during the breeding season. Human Menopausal Gonadotropin (HMG) reveled good result in estrus synchronization, pregnancy, lambing and time of parturition. Dystocia, pregnancy toxemia and other birth problems (like hypocalcemia) need more investigations to find out if there is a correlation between the type of hormones used for estrus synchronization program and the incidence of these cases.

\section{Acknowledgments}

The authors are very grateful to the university of Mosul/ college of veterinary medicine for their a provide facilities, which helped to improve quality of this work, and also the authors very thankful to animal's owners who helped us to complete this study.

\section{Conflict of Interest}

No conflict

\section{References}

1. Al-Mola MK, Azawi OI. Effect of season and mating system in Iraqi Awassi ewes super ovulated with FSH on fertilization rate and embryo $\begin{array}{lllll}\text { recovery. Iraqi J Vet Sci. 2010;24(2):75-79. DOI: } & \end{array}$ http://doi.org/10.33899/ijvs.2010.5590

2. Kalyan De, Kumar D, Stethi D. Estrus synchronization and fixed-time insemination in sheep under field condition of semi-arid tropical region. Trop Anim Health Proud. 2015;47(2):469-72. DOI: 10.1007/s11250014-0735-x

3. Wildeus S. Current Concepts in synchronization of estrus: Sheep and Goat. J Anim Sci. 2000;77:1-14. DOI: 10.2527/jas2000.00218812007700ES0040x

4. Abu EL-Ella AA, Teleb DF, Abdel- Hafez MAM, Deghedy AM. Appraisal of different protocols for estrus synchronization in local Rahmani sheep. Egypt J Sheep Goat Sci. 2016;11(3):116-131. DOI: $10.12816 / 0035352$

5. Escobar EN, Kassa E, Obrain DO, Taylor H. 260 the induction and synchronization of estrus in sheep during the fall and late spring (season and out of season) using controlled internal drug release (CIDR) on Delmarva. J Anim Sci. 2017;95(4) 128. DOI: 10.2527/asasann.2017.260

6. Wei S, Chen S, Wei B, Liu Z, Bai T, Lin J. Estrus synchronization schemes and application efficacies in anestrus lanzhou fat-tailed ewes. J Appl Anim Res. 2016;44(1):466-473. DOI: 10.1080/09712119.2015.1091350

7. Scudamore CL, Robinson JJ, Aitken RP, Robertson IS. the effect of method of Oestrus synchronization on the response of ewe to superovulation with porcine follicle stimulating hormone. Anim Reprod Sci. 1993;34:127-133. DOI: 10.1016/0378-4320(93)90071-X

8. Driancourt MA, Fry RC, Clarke IJ, Cahil LP. Follicular growth and regression during the 8 days after hypophsectomy in sheep. J Reprod Fertil. 1987;79:635-641. DOI: 10.1530/jrf.0.0790635

9. Timurkan H, Yildiz H. Synchronization of oestrus in hamdani ewes: the use of different pmsg doses. Bull Vet Pul. 2005;49: 311-314. DOI: $\underline{10.1017 / \mathrm{S} 1751731118001908}$

10. Kafaji SSA, Al-Sa'aidi JAA, Khudair KK. Reproductive hormones profile of Iraqi Awassi ewes immunized against synthetic inhibin- $\alpha$ subunit or steroid-free bovine follicular fluid. Iraqi J Vet Sci. 2017;31(2):123-128. DOI: 10.33899/ijvs.2017.145609

11. Levi Sett PE, Alviggi C, Colombo GL, Pisanelli C, Ripellino C, Longboardi S, Canonic PL, Deplacido G. Human recombinant follicle stimulating hormone ( $\mathrm{rFSH}$ ) comparing urinary human menopausal gonadotropin (HMG) for ovarian stimulation in assisted reproduction. J Endocrinology Invest. 2015;38(5):497-503. DOI: 10.1007/s40618014-0204-4

12. Ashour G, El-bassiony MF, Dessoki SM, El-wakeel MA. Application of different hormonal protocols for improving reproductive performance of barki ewes. World Vet J. 2018;8(3):55-64. [available at]

13. Wei S, An L, Zhang T, Dai T, Chen S. Cloprostenol and pregnant mare gonadotropin promote estrus synchronization, uterine development, 
and follicle stimulating hormone receptor expression in mice. GMR J. 2015;14(2):7184-7195. DOI: $10.4238 / 2015$

14. Daghash H, Fahmy S, Hassan T, Ali M. Impact of GnRH, PMSG and HCG treatments on follicular diameter, conception and lambing rates of Egyptians ewe lambs using intravaginal sponges. Egypt J Sheep Goat Sci. 2017;12(1):1-8. DOI: 10.21608/EJSGS.2017.26321

15. Taher JK. Different oestrus induction methods in awassi ewes during the out of breading season. Bas J Vet Res. 2014;1(2):66-74. DOI: 10.33762/bvetr.2014.98795

16. Koyuncu M, Altıcekic O. Effects of progestogen and PMSG on estrous synchronization and fertility in Kivircik ewes during natural breeding season. Asian-Aust J Anim Sci. 2010;23(3): 308-311. DOI: 10.5713/ajas.2010.90393

17. Henderson KM. Gonadotrophic regulation of ovarian activity. Brit Med Bull. 1979;35:161-166. DOI: 10.1093/oxfordjournals.bmb.a071564

18. Naderipour, H, Yadi, J, Shad, AGK, Sirjani, MA. The effects of three methods of synchronization on estrus induction and hormonal profile in Kalkuhi ewes: A comparison study. African J Biotech. 2012;11: 530 533. DOI: $10.5897 / \mathrm{AJB} 11.2718$

19. Alfuraiji MM, Atkinson $\mathrm{T}$, Broadbent PJ, Hutchinson JSM. Superovulation in cattle using PMSG followed by PMSG monoclonal antibodies. Anim Rep Sci. 1993;33(1-4):99-109. DOI: 10.1016/03784320(93)90109-5

20. Wheaton JE, Carlson KM, Windels HF, Johnston LJ. CIDR: A new progesterone-releasing intravaginal device for induction of estrus and cycle control in sheep and goat. Anim Reprod Sci. 1993;33(1-4):127141. DOI: $10.1016 / 0378-4320(93) 90111-4$

21. He B, Cheng Junping, Li H, Weihong T, lintao X, Shikai W. Effects of human menopausal gonadotropin on zona pellucida and pregnancy outcomes of ovarian stimulation protocols. Iran J Reprod Med. 2015;13(6):337-344. [available at]

22. Dias LMK, Sales JNS, Viau P, Barros MBP, Nicolau SS, Simoes LMS, Alves NG, Alonso MA, Oliveira CA. Although it induces synchronized ovulation, hCG reduce the fertility of Santa Ines ewes submitted to TAI. Arq Bras Med Vet Zootec. 2018;70(1):122-130. DOI: 10.1590/16784162-9679

23. Park Sun-J, Kim Tae-Shin, Kim Jin-Man, Chang Kyu-Tae, Lee Hyunshik, Lee Dong-Seok. Repeated Superovulation via PMSG/hCG Administration Induces 2-Cys Peroxiredoxins Expression and Overoxidation in the Reproductive Tracts of Female Mice. Mol Cells. 2015;38(12):1071-1078. DOI: 10.14348/molcells.2015.0173

24. Summon HMD, Dutta RK, Muralidhar K, Gupta RD. Decreased ascorbic acid biosynthesis in response to PMSG in the pre- pubertal female rat ovary. Res Vet Sci. 2020;131:15-20. DOI: 10.1016/j.rvsc.2020.03.028

25. Majeed AF, Taha MB. Obstetrical disorders and their treatment in Iraqi Awassi ewes. Small Rumin Res. 1995;17:65-69. DOI: 10.1016/09214488(95)00645-2

26. Abdul-Rahman SY, Sultan KH. Effect of vitamin A and grazing in some physiological characters and milk production of Meriz does. Iraqi J Vet Sci. 2019;33(2):395-365. DOI: 10.33899/ijvs.2019.163080

27. Naoman UD, Al-Watar BD, Lzaim EH, Hussein EK. Fetal anomalies in prolonged gestation in Awassi ewe: A case report. Iraqi J Vet Sci. 2018;32(2):195-197. DOI: $10.33899 /$ ijvs.2019.153849

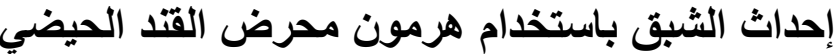 البشري في النعاج العواسية العراتية التية}

\author{
الياس خضر حسين، رضوان رياض كاظم و عدي طلعت نعمان \\ فرع الجراحة وعلم تتاسل الحيوان، كلية الطب البيطري، جامعة

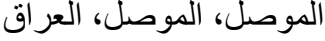

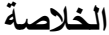

إن الهذف من الدراسة هو أحداث الثبق في النعاج العواسية العر اقية

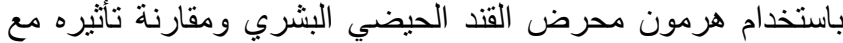

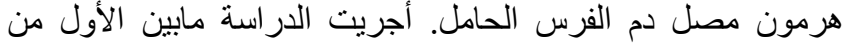

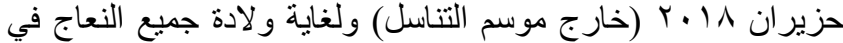

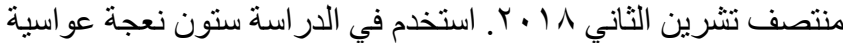

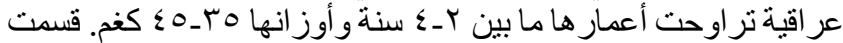

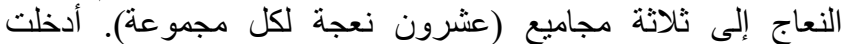
الإسفنجات المهبلية المشبعة بهرمون البروجستيريرون إلى إلى جميع النعاج

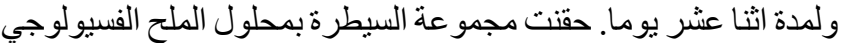

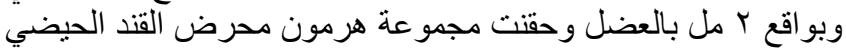

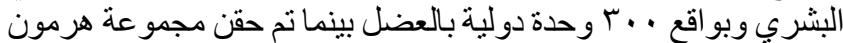

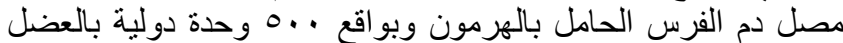

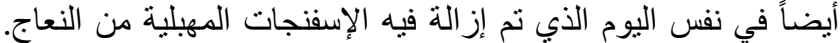

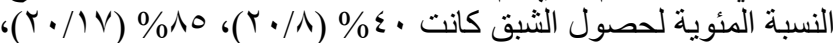

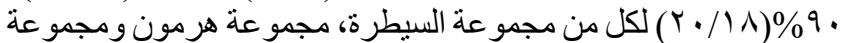

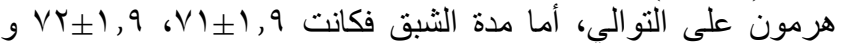

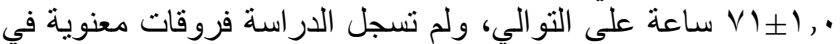

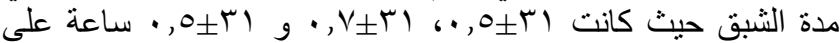

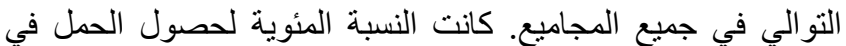

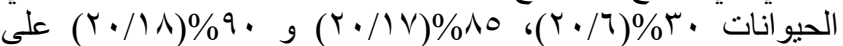

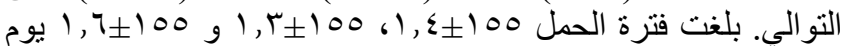

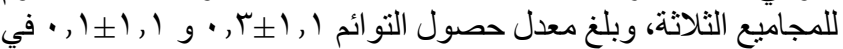

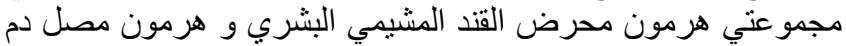

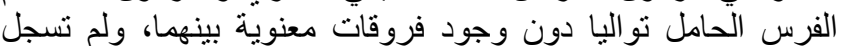

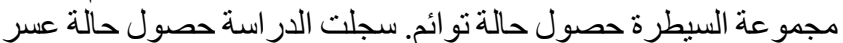

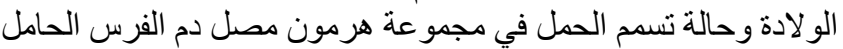

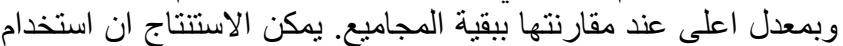

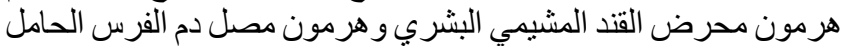

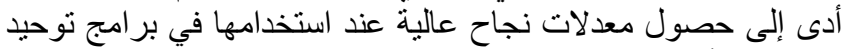

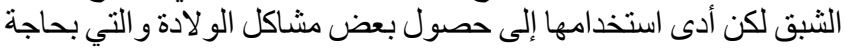
إلى مزيد من الدر اسة و الاستقصاء مستقبلا. 